\title{
O papel social das bibliotecas públicas no século XXI e o caso da Superintendência de Bibliotecas Públicas de Minas Gerais
}

Marina Nogueira Ferraz

Bibliotecária e mestranda em Ciência da Informação na ECI/UFMG. Diretora do Sistema Estadual de Bibliotecas Públicas Municipais.

http://dx.doi.org/10.1590/1981-5344/2280

O presente trabalho aborda a biblioteca pública, seu significado, importância social e desafios na contemporaneidade e tenta esclarecer, ainda que de forma sucinta, o surgimento das bibliotecas públicas e os conceitos utilizados para este termo, que irão embasar sua atuação e a construção de suas políticas. Discute qual a importância social da biblioteca pública no século XXI e como sua atuação tem se tornado fundamental como espaço de diálogo e exercício da cidadania, além de se configurar em um centro de promoção cultural, na medida em que acolhe e articula as diversas manifestações artísticas e cultuais. Aponta os principais desafios que as bibliotecas públicas enfrentam hoje, seja na elaboração de políticas públicas voltadas para o livro e para leitura, seja na captação de recursos via mecanismos alternativos de financiamento, como forma de viabilizarem suas ações. Ao final, descreve a atuação da Superintendência de Bibliotecas Públicas e Suplemento Literário de Minas Gerais como gestora da Biblioteca Pública Estadual Luiz de Bessa, considerada a maior biblioteca do estado, e também as ações do Sistema Estadual de Bibliotecas Públicas Municipais, que possui uma rede de 839 bibliotecas, distribuídas em 801 municípios mineiros.

Palavras-chave: Biblioteca Pública. Papel social. Atuação política.

The social role of public libraries in the
twenty-first century and the case of
the Superintendent of Public Libraries
of Minas Gerais 
This work addresses the public library, its significance, importance and challenges in contemporary social, tries to clarify, albeit briefly, the emergence of public libraries and concepts used for this term, which will support its operations and building policies. Which discusses the social importance of the public library in the twenty-first century, and how their performance has become critical as a space for dialogue and citizenship, as well as set up a center of cultural promotion, in that it gathers and articulates the various manifestations artistic and cultic. Highlights the main challenges that public libraries face today, or in the elaboration of public policies for the book and reading, either in funding through alternative funding mechanisms, in order to make viable their actions. At the end, describes the performance of the Superintendent of Public Libraries as manager of the Biblioteca Pública Estadual Luiz de Bessa, considered the largest library in the state, and also the actions of the Sistema Estadual de Bibliotecas Públicas Municipais, which has a network of 839 libraries, distributed 801 municipalities of Minas Gerais.

\section{Key-words: Public library. Social role. Political action.}

Recebido em 21.11.2014 Aceito em 22.11.2014

\section{Introdução}

Com o desafio de falar da biblioteca pública, seu significado, importância social e desafios na contemporaneidade, o presente trabalho tentará esclarecer, ainda que de forma sucinta, o surgimento das bibliotecas públicas e os conceitos utilizados para este termo, na medida em que a partir deles, as instituições públicas irão balizar sua atuação e a construção de suas políticas. Discutirá também qual a importância social da biblioteca pública no século XXI e como sua atuação tem se tornado fundamental como espaço de diálogo e exercício da cidadania, além de se configurar em um centro de promoção cultural, na medida em que acolhe e articula as diversas manifestações artísticas e culturais. Este trabalho também irá apontar os principais desafios que as bibliotecas públicas enfrentam hoje, seja na participação da elaboração de políticas públicas voltadas para o livro e para leitura, seja na captação de recursos via mecanismos alternativos de financiamento, como forma de viabilizarem suas ações. Ao final, irá descrever a atuação da Superintendência de Bibliotecas Públicas e Suplemento Literário como gestora da Biblioteca Pública Estadual Luiz de Bessa, considerada a maior biblioteca do estado, e também as ações do Sistema Estadual de Bibliotecas Públicas 
Municipais, que possui uma rede de 839 bibliotecas, distribuídas em 801 municípios mineiros ${ }^{1}$.

\section{Surgimento das bibliotecas públicas e seu conceito}

As bibliotecas são instituições antigas, mais antigas que o próprio livro. Desde a Antiguidade já existiam bibliotecas, mas até a Renascença estas eram tidas como sagradas, com acesso restrito aos monges e sacerdotes e se apresentavam imbuídas de uma aura de mistério. No que se refere às bibliotecas públicas, uma das primeiras que se tem notícia teria sido idealizada pelo general Júlio César, que mesmo após sua morte, foi construída pelo orador Asínio Pólio, no ano 39.d.C. "estabelecendo simbolicamente a primeira biblioteca pública do templo romano da Liberdade" (MARTINS, 2002, p. 78).

No entanto, importantes obras de referência se contradizem no que diz respeito ser a primeira biblioteca pública, e os questionamentos ficam entre a de Ulpiana, fundada por Trajano, a Ambrosiana, de Milão, fundada pelo cardeal Borromeu em 1608, a Biblioteca Marciana, de Florença, no séc. XV e a Vaticana, fundada pelo papa Nicolau, por volta de 1450 (MARTINS, 2002, p. 78-79).

No Brasil, considera-se a primeira biblioteca aberta ao público a Biblioteca Nacional, quando em 1807 a Corte portuguesa foge para o Rio de Janeiro, trazendo a Real Biblioteca, mas somente em 1824 que ela é aberta ao público. Segundo Cesarino (2007) "em 1811 é criada em Salvador a primeira instituição com o nome de biblioteca pública". A partir desde momento essas instituições passam a disseminar-se por todo país, formando hoje uma rede de mais de 5.400 bibliotecas no Brasil.

Esclarecido o surgimento das bibliotecas públicas, ainda que sob um véu de incertezas e contradições, daremos um salto vertiginoso para os tempos atuais e nos dedicaremos a discutir qual o papel social desempenhado por estas bibliotecas, iniciando pelos conceitos que irão nos embasar para tal discussão.

A biblioteca pública tem papel primordial no que se refere à democratização do acesso à informação, na medida em que recebe, sem distinção, qualquer pessoa independente de sua classe social, sexo, orientação sexual ou religião, tornando-se a mais democrática de todos os tipos de biblioteca. Desde o bebê, o estudante, passando pela dona de casa, empresário,

\footnotetext{
${ }^{1}$ Dados do Recadastramento de 2009 do Sistema Estadual de Bibliotecas Públicas Municipais.
} 
aposentado até o idoso, todos podem frequentar uma biblioteca pública na medida de seu interesse. Para atender a todos esses públicos, a biblioteca pública deverá contar com um acervo variado e generalista, pois será tarefa quase impossível aprofundar-se em todas as áreas do conhecimento. Vários suportes e mídias devem estar presentes, acompanhando as evoluções da tecnologia. A biblioteca pública também deverá desempenhar o papel de preservação da memória local, guardando e disponibilizando a produção cultural de sua comunidade e região.

O Manifesto da IFLA/UNESCO para as Bibliotecas Públicas define:

A biblioteca pública - porta de acesso local ao conhecimento fornece as condições básicas para uma aprendizagem contínua, para uma tomada de decisão independente e para o desenvolvimento cultural dos indivíduos e dos grupos sociais. (...) A biblioteca pública é o centro local de informação, tornando prontamente acessíveis aos seus utilizadores 0 conhecimento e a informação de todos os gêneros. Os serviços da biblioteca pública devem ser oferecidos com base na igualdade de acesso para todos, sem distinção de idade, raça, sexo, religião, nacionalidade, língua ou condição social. Todos os grupos etários devem encontrar documentos adequados às suas necessidades. As coleções e serviços devem incluir todos os tipos de suporte e tecnologias modernas apropriadas assim como materiais tradicionais. É essencial que sejam de elevada qualidade e adequadas às necessidades e condições locais. As coleções devem refletir as tendências atuais e a evolução da sociedade, bem como a memória da humanidade e o produto da sua imaginação.

Muito mais do que definir o público alvo ou tipos de acervos, o Manifesto "proclama a confiança que a Unesco deposita na Biblioteca Pública, enquanto força viva para a educação, a cultura e a informação, e como agente essencial para a promoção da paz e do bem-estar espiritual nas mentes dos homens e das mulheres" (IFLA, 1994). As definições e diretrizes contidas neste manifesto têm servido, desde 1994, como parâmetro para as bibliotecas públicas de todo o mundo, no entanto, nota-se ainda que, na prática, muitas bibliotecas estão longe de exercerem sua missão, como propõe este documento.

\section{Importância social}

Para além de guardar livros ou ser um apêndice da biblioteca escolar, a biblioteca pública tem hoje papel fundamental na sociedade, na medida em que se torna um local de interação, debates e manifestações 
culturais e artísticas, extrapolando seu papel de democratização da cultura letrada. É um centro de promoção cultural, atuando como veículo para o exercício da cidadania. No entanto, para se apropriar desta nova roupagem, é necessário realizar alguns questionamentos, no intuito de definir diretrizes e políticas que contemplem essa nova atuação. Pinheiro faz algumas perguntas pertinentes para começarmos a discutir:

Qual o papel da biblioteca pública em cidades onde as necessidades de cada região diferem substancialmente? Quais as medidas a serem implementadas que coloquem a biblioteca mais sintonizada com os interesses de uma população heterogênea, que tem em seus anseios convergências e contradições? (PINHEIRO, 2009, p. 1)

A importância social da biblioteca pública está justamente em se conseguir pensar nas necessidades da comunidade na qual ela está inserida, e saber reconhecer os interesses da população. Indo um pouco mais além, deve-se pensar na demanda latente, ainda não reconhecida pela população, mas que deve ser oferecida e incorporada às políticas culturais vigentes. Assim, Pinheiro continua;

A demanda por informação, a formação de leitores e a necessidade de fruição de um espaço cultural são fatores que colocam a biblioteca e seus mediadores (bibliotecários e demais funcionários) como itens de vital importância para a vida de uma cidade.

Porém, para fazer jus a essa condição, a biblioteca pública precisa passar por correções de rumo e pela adequação de seus serviços.

A condução da biblioteca pública rumo aos interesses e necessidades da população passa principalmente por uma análise do perfil dessa população. Questões como:

1 - quem é essa população;

2 - como a população vê a biblioteca pública nesse momento;

3 - quais suas demandas informacionais e também suas necessidades de fruição;

4 - que biblioteca essa população quer para si?

A partir do conhecimento das pessoas que frequentem e que potencialmente possam frequentar a biblioteca, começa-se a delinear seu verdadeiro perfil e identidade. Conhecer a cidade e conhecer o citadino. (PINHEIRO, 2009, p. 1) 
A bibliotecária colombiana Silvia Castrillón, no livro "O direito de ler e de escrever (2011)", debate com profundidade a questão do direito à leitura e do papel social das bibliotecas públicas, colocando como primordial algumas mudanças do que hoje se propõem as bibliotecas públicas, devendo torná-las espaços verdadeiros de interação social. Para Silvia,

Um país requer bibliotecas que possam ir mais além desse plano mínimo de trabalho. Bibliotecas que, em primeiro lugar, se convertam em meios contra a exclusão social, isto é, que se constituam em espaços para o encontro, para o debate sobre os temas que dizem respeito a maiorias e minorias; bibliotecas onde crianças, jovens e adultos de todas as condições, leitores e não leitores, escolares e não escolares, encontrem respostas a seus problemas e interesses e lhes sejam abertas novas perspectivas (CASTRILLÓN, 2009).

Algumas experiências nesse sentido já são realidade no Brasil e no mundo. No Chile e Colômbia, grandes bibliotecas foram construídas em bairros com alto índice de violência, obrigando jovens de gangues rivais a frequentarem o mesmo espaço. Foram construídas bibliotecas com acervos de boa qualidade e bem conservadas, sala de computadores, brinquedoteca e espaço para os eventos da comunidade. Assim, a interação no espaço diminuiu consideravelmente os índices de violência.

Utilizando estes exemplos como referência, a Secretaria de Cultura do Estado do Rio de Janeiro ${ }^{2}$ inaugurou em 2010 a Biblioteca Parque de Manguinhos. Com 2,3 mil metros, a biblioteca possui um grande e confortável salão principal, um amplo salão de leitura, salas para cursos e estudos, espaço multimídia, ludoteca, café literário, um cineteatro com 200 lugares e uma sala chamada "Meu Bairro", que atende às necessidades de reuniões e fóruns comunitários. Também situada em uma área de risco, a biblioteca tem contribuído para a diminuição dos índices de violência, uma vez que proporciona a interação da comunidade. Seguindo os mesmos moldes, em 2012 foi inaugurada, também no Rio de Janeiro, a Biblioteca Parque da Rocinha. Com 1,6 mil metros quadrados, a Biblioteca Parque da Rocinha possui cinco andares, nos quais se pode encontrar uma DVDteca, um cineteatro, uma sala multiuso para cursos, estúdio de gravação e edição audiovisual, setor de internet comunitária (com 48 computadores e 12 notebooks), cozinha-escola e café-literário, além do acervo de livros.

Essas concepções de biblioteca só são possíveis quando a promoção da leitura como um direito básico de todos os cidadãos (CASTRILLON, 2011) passa a ser o ponto de partida para se pensar todas as demais ações, como nos esclarece Mangas;

\footnotetext{
${ }^{2}$ Disponível em: <http://www.cultura.rj.gov.br/>. Acesso em: 13 ago. 2014.
} 
(...) uma sociedade da informação e do conhecimento, como hoje é conhecida a nossa sociedade, implica uma sociedade de leitores. Mas aprender a ler e a escrever é, antes de mais nada, aprender a ler o mundo e aprender a compreender o seu contexto, não através da manipulação repetitiva ou lúdica das palavras, mas através de um processo dinâmico e dialéctico em que a linguagem e a realidade se articulem. Ou seja, a leitura deve ser uma actividade emancipadora, um instrumento essencial para que os indivíduos se possam reconhecer como cidadãos, isto é, como detentores de direitos e deveres. Dito de outro modo: a leitura deve ser capaz de dotar os indivíduos de uma maior consciência política (MANGAS, 2011).

O Manifesto da IFLA/UNESCO para as Bibliotecas Públicas, lançado em 1994, tem servido de parâmetro para pensar o conceito das bibliotecas públicas, seu papel social e sua missão. Com o intuito de ampliar as concepções de atuação das bibliotecas públicas, a IFLA (2008) lança o Manifesto sobre Transparência, bom governo e combate a corrupção, reafirmando o papel social da biblioteca pública, mas neste caso voltado para a transparência dos governos e para o acesso à informação;

A IFLA afirma que as bibliotecas são em sua verdadeira essência instituições transparentes, dedicadas a colocar à disposição de cada um e de todos as informações educacionais, científicas, técnicas e socialmente mais relevantes, mais acuradas e imparciais. Os materiais de informação e acessos providos pelas bibliotecas e os serviços de informação contribuem para o bom governo aumentando o conhecimento dos cidadãos e enriquecendo suas discussões e debates. As bibliotecas e os serviços de informação devem ampliar sua missão de modo a se tornarem componentes mais ativos do bom governo e na luta contra a corrupção. Em particular eles podem desempenhar um papel significativo informando aos cidadãos sobre seus direitos e garantias (IFLA, 2008).

Para que a biblioteca pública possa desempenhar o papel de promoção da cidadania e ser um equipamento cultural aberto às diversas manifestações humanas, é mais que necessário, é primordial que os governos invistam recursos e formulem políticas públicas que garantam esses recursos. Que sejam políticas de estado, para além das políticas de governo, que dominam o contexto político há tanto tempo.

A participação social também tem papel fundamental, e esta participação deve ter a biblioteca pública como espaço para discussão. Castrillón defende sua posição propondo 
(...) que a biblioteca pública, de maneira mais comprometida e ativa, acompanhe o indivíduo e a comunidade organizada em direção a uma leitura crítica da realidade, a partir do debate público dos temas que a afetam, com vistas a uma participação consciente em sua transformação. Em outras palavras, que contribua para criar cidadãos mais bem formados e mais bem informados (CASTRILLÓN, 2011, p. 84).

Todas as reflexões acerca do papel social da biblioteca pública nos levam a perceber que, sem a participação da sociedade e sem o investimento do estado em políticas públicas que realmente garantam o acesso à leitura, à informação e à cultura, não será possível construir uma sociedade mais democrática e sem tantas desigualdades. A Biblioteconomia, deve-se debruçar na pesquisa deste campo de atuação, como forma de investigar e subsidiar a atuação dos bibliotecários que atuam nesta área e incentivá-los a desenvolverem pesquisas, renovando sua prática e contribuindo para a formação de novos profissionais, aptos a lidarem com esta atividade tão desafiadora, mais ao mesmo tempo tão prazerosa e recompensadora.

\section{Desafios na contemporaneidade}

Foi no viés da interação entre a sociedade civil, a cadeia criativa, produtiva e mediadora da leitura que foi pensado o Plano Nacional do Livro e da leitura/PNLL ${ }^{3}$, no ano de 2006, pelos Ministérios da Cultura e Educação, tendo como eixos norteadores estimular a democratização do acesso ao livro, o fomento e a valorização da leitura e o fortalecimento da cadeia produtiva do livro. As bibliotecas públicas inserem-se no Eixo 1: Democratização do acesso, que prevê a construção, modernização e revitalização das bibliotecas brasileiras, com investimentos garantidos em diversas ações.

Após um período de inatividade a discussões sobre o PNLL e seus desdobramentos estaduais e municipais voltaram em 2013, após significativas reestruturações administrativas no Ministério da Cultura. $O$ grande desafio tem sido implantar os planos estaduais e municipais, na medida em que é necessária uma ampla discussão sobre o assunto, envolvendo todos os atores, fase esta anterior à sua institucionalização propriamente dita. O que se percebe é que os planos já instituídos são, muitas vezes impostos, sem participação social ou discussão da melhor linha a ser seguida. Os estados e municípios que ainda não possuem seus planos padecem de uma situação financeira difícil, pois as bibliotecas ficam com seus orçamentos condicionados à vontade política de suas gestões, sofrendo cortes que inviabilizam sua atuação efetiva na política cultural na qual estão inseridas.

\footnotetext{
${ }^{3}$ Disponível em: <http://www.pnll.gov.br/>. Acesso em: 15 ago. 2013.
} 
Urge que o PNLL seja transformado em lei, para que este programa não seja mais uma ação de governo, e sim possa ter a garantia de sua continuidade. É urgente também que os estados e municípios que ainda não possuem seus planos comecem a articular todos os agentes interessados, para podermos avançar nas questões que dizem respeito ao acesso à leitura e à informação.

Como forma de suprir a falta de recursos orçamentários governamentais, muitas instituições, inclusive as bibliotecas públicas e suas redes, estão voltando-se para outras formas de financiamento, entre elas as leis de incentivo e os fundos de cultura. A Lei Federal de Incentivo à Cultura, também chamada de Lei Rouanet, é responsável pela aprovação de inúmeros projetos referentes às bibliotecas públicas, desde a construção de prédios próprios, passando pela modernização de seus serviços, até o desenvolvimento de projetos de ação cultural e ampliação do acesso. Em Minas Gerais a Lei Estadual de Incentivo à Cultura e o Fundo Estadual de Cultura têm contribuído imensamente para o financiamento de ações nas bibliotecas públicas. O grande desafio está na elaboração dos projetos, habilidade pouco encontrada nos gestores das bibliotecas públicas municipais.

Este tema tem sido abordado em vários cursos ministrados pela Superintendência de Bibliotecas Públicas e Suplemento Literário, e vêm-se notando uma melhora no nível dos projetos encaminhados a estes veículos de financiamento.

Como se pode perceber, os desafios são inúmeros, desde a mobilização da sociedade, passando pela institucionalização de políticas públicas, até a garantia de recursos para atividades essenciais, e todos estes assuntos deverão ter na biblioteca pública espaço para discussão.

\section{Experiência da SUBSL}

Anterior à institucionalização da Superintendência de Bibliotecas Públicas de Minas Gerais/SUB, que em janeiro de 2014 passou a coordenar também as ações do Suplemento Literário e passou a ser denominada como Superintendência de Bibliotecas Públicas e Suplemento Literário/SUBSL, devemos nos ater à criação da Biblioteca Pública Estadual Luiz de Bessa/BPELB. Criada em 1954, por meio da Lei no 1087, pelo então governador Juscelino Kubitschek, teve seu prédio projetado pelo arquiteto Oscar Niemeyer, sendo inaugurado em 1961, passando a integrar o conjunto arquitetônico da Praça da Liberdade.

A BPELB, como nas concepções de JK, tornou-se um equipamento cultural dinâmico, vivo, onde recebe e agrega várias manifestações culturais. Atende a um público de cerca de 400 mil pessoas por ano e guarda um acervo de mais de 230 mil itens, tonando-se referência para as mais 830 bibliotecas municipais do estado de Minas Gerais, além de fazer parte do Circuito Cultural Praça da Liberdade, hoje um programa estruturador do Governo de Minas.

Na mensagem enviada à Assembleia de MG, Juscelino diz que, 
[...] a finalidade da biblioteca moderna não se limita a completar os estudos secundários e universitários, ou a proporcionar ao trabalhador intelectual as obras e documentos de que precisa. Tem ao mesmo tempo, uma função cultural altamente democrática (CESARINO, 2006, p. 22).

Constata-se aí a função cultural e de participação social da biblioteca pública, que foi discutida durante todo o texto e que a BPELB se empenha para desenvolver, com todo o comprometimento e recursos que lhe são destinados.

Para atender a todas as demandas de uma biblioteca viva, dinâmica e inserida na política cultural do Estado, a BPELB conta com dois prédios e diversos serviços e espaços, a saber: o setor de Empréstimo Domiciliar, com grande acervo das mais diversas áreas do conhecimento, com ênfase para a literatura; o setor de Referência e Estudos, que possui obras de referência e para consulta, abrigando grande parcela dos leitores da Biblioteca; o setor de Periódicos, com a assinatura de inúmeros jornais e revistas nacionais e internacionais de grande qualidade; o setor Infanto juvenil, que tem seu acervo selecionado e dinamizado de forma particular para o público a que se destina; o setor Braille, referência em acessibilidade, tem um grande acervo e serviços especializados para pessoas com deficiência visual; as Coleções Especiais, que abarcam coleções particulares, especiais, de obras raras, a Coleção Mineiriana, que guarda a produção bibliográfica de autores mineiros e sobre Minas Gerais, entre outras; a Hemeroteca Histórica, setor responsável por preservar os jornais e revistas históricos e raros, especialmente os editados em Minas. Todos os setores da Biblioteca possuem seus acervos informatizados, utilizando o software Pergamun, que pode ser consultado pela internet ${ }^{4}$.

Para além dos setores, existem outros espaços que auxiliam a denominação da Biblioteca como um verdadeiro centro cultural: o Teatro José Aparecido de Oliveira, que comporta 220 pessoas e recebe espetáculos e eventos das diversas manifestações cultuais; o Teatro de Arena, espaço amplo ao ar livre, próprio para apresentações teatrais; e as galerias Paulo Campos Guimarães e Passarela Cultural, que recebem, por meio de edital, exposições artísticas e literárias durante todo o ano.

Para ampliar o acesso, a BPELB conta com atividades de extensão bibliotecária, que extrapola seu limite geográfico de atuação e leva para comunidades distantes e outras instituições a oportunidade de interagir com a produção literária e com as atividades que dela derivam, e são elas: o Carro-Biblioteca, que atende a 6 bairros da região metropolitana de Belo Horizonte, que, além de levar informação e cultura, trabalha na articulação da comunidade para que demandem bibliotecas em seus bairros; o serviço de Caixa-Estante, que hoje está disseminada em 15 instituições públicas e não governamentais e tem como objetivo criar demanda de leitura nas instituições atendidas, incentivando-as e apoiando-as na implantação de biblioteca própria.

\footnotetext{
${ }^{4}$ Disponível em: <http:www.cultura.mg.gov.br>. Acesso em: 13 ago. 2013.
} 
No sentido de incentivar a leitura, a BPELB desenvolve inúmeros projetos, entre eles a Hora do Conto e da Leitura, os projetos Aula na Biblioteca e Em Destaque, o ciclo de palestras Encontros com a Leitura, a Hora do Conto e da Leitura Braille e muitos outros.

Em 1984 a SUB foi institucionalizada, passando a ser uma das unidades da Secretaria de Estado de Cultura. A partir deste momento a SUB passou a coordenar as ações da BPELB, e mais tarde do Sistema Estadual de Bibliotecas Públicas Municipais/SEBPM, com o intuito de interiorizar a ação bibliotecária no estado. Hoje, 839 bibliotecas públicas municipais, em 801 municípios, formam o SEBPM, que trabalha incansavelmente no propósito de ampliar e modernizar a rede de bibliotecas públicas, por meio do projeto Construindo uma Minas Leitora. O SEBPM oferece assessorias para as bibliotecas municipais, visitas técnicas e de fiscalização, promove cursos de capacitação e desenvolve as Exposições Literárias Itinerantes, como uma ação de incentivo à leitura para a capital e para os demais municípios. O Sistema tem como principal desafio atuar em um estado de dimensões continentais, com diferenças culturais e econômicas muito marcadas e grande número de municípios. A maioria dos municípios tem como principal dificuldade 0 pouco investimento em suas bibliotecas, desde a contratação de pessoal, passando pela compra de acervo e desenvolvimento de ações de mediação e incentivo à leitura. Muitas cidades continuam a mercê da vontade política de seus dirigentes, que desconhecem o valor da leitura e julgam a biblioteca como apenas uma fonte de gasto e preocupação. A equipe do Sistema Estadual de Bibliotecas Públicas Municipais tem trabalhado de forma incisiva para que o funcionamento e manutenção das bibliotecas municipais continuem existindo e melhorando cada dia mais.

A Superintendência de Bibliotecas Públicas possui recursos financeiros previstos no orçamento anual da Secretaria de Estado de Cultura (PPAG), no entanto, muitos de seus projetos foram viabilizados por meio das Leis de Incentivo à Cultura Federal e Estadual. Todo o processo de informatização do acervo, ocorrido no início de ano 2000 e a reforma do prédio Sede, foram realizados com recursos captados por meio da Lei Federal de Incentivo à Cultura, ou Lei Rouanet. Atualmente estão em andamento os projetos de reestruturação tecnológica da Biblioteca Pública Estadual Luiz de Bessa e a realização do IV Encontro do Sistema Estadual de Bibliotecas Públicas Municipais. Para captação, está aprovado o projeto de restauração do acervo Memória Infantil das Coleções Especiais da BPELB, todos pela Lei Rouanet.

Os desafios e limitações da SUBSL são muitos, no entanto, a instituição possui uma equipe apaixonada e comprometida, que desenvolve suas ações com qualidade, articulando parcerias e priorizando sempre oferecer ao público o melhor, dentro de suas possibilidades. É preciso avançar muito ainda, especialmente no que diz respeito ao aumento dos recursos financeiros, que deveriam ser pensados balizandose no tamanho da responsabilidade que é articular uma rede de mais de 
800 bibliotecas e manter a maior biblioteca do estado como uma referência para as demais.

\section{Considerações Finais}

A partir de todas estas reflexões, podemos afirmar que a biblioteca pública desenvolve, no século XXI, papel fundamental para a participação social, articulação cidadã, além de se configurar como um equipamento cultural essencial na vida cultural dos municípios brasileiros. É preciso que políticas públicas sejam formuladas realmente com o intuito de aportar recursos financeiros e condições materiais para que as bibliotecas funcionem com qualidade, e possam exercer o papel desafiador que a sociedade está lhe demandando e que faz parte de sua missão primeira.

A Ciência da Informação tem muito a contribuir, tomando para si a biblioteca pública e a atuação do bibliotecário como um de seus objetos de investigação e dando-lhe, dentro dos cursos de Biblioteconomia, a importância que se faz necessária. Para encerrar, citaremos a professora Ana Maria Cabral (2007), quando ela diz da importância da informação para evolução da sociedade.

A informação só pode ser considerada como instrumento de mudança e transformação social se for colocada à disposição dos cidadãos através de serviços públicos fornecidos pelo Estado, visto se tratar de um direito de cidadania. O acesso à informação é fundamental à participação dos indivíduos nos processos decisórios, sendo elemento fundamental para que possam fazer suas escolhas e opções. Esta é uma das principais formas que possibilitam o exercício pleno da cidadania, que historicamente, em nosso país, têm sido negados à maioria dos cidadãos, especialmente devido à exclusão social (CABRAL, 2007, p. 46).

\section{Referências}

BRASIL. Ministério da Cultura. Plano Nacional do Livro e Leitura - PNLL. Plano Nacional do Livro e Leitura: textos e história : 2006-2010. São Paulo: Cultura Acadêmica, 2010. 325 p.

CABRAL, Ana Maria R. Ciência d a informação, a cultura e a sociedade informacional. In: REIS, Alcenir Soares; CABRAL, Ana Maria (Org.). Informação, cultura e sociedade: interlocuções e perspectivas. Belo Horizonte: Novatus, 2007. p. 29-48.

CASTRILLÓN, Silvia. O direito de ler e de escrever. São Paulo: Pulo do Gato, 2011. 100p.

CESARINO, Maria Augusta da Nóbrega. Biblioteca Pública Estadual Luiz de Bessa: 50 anos de cultura. Belo Horizonte: Secretaria de Estado da 
Cultura de Minas Gerais, Superintendência de Bibliotecas Públicas, 2006. $109 \mathrm{p}$.

CESARINO, Maria Augusta da Nóbrega (Org.). Bibliotecas públicas municipais: orientações básicas. Belo Horizonte: Secretaria de Estado da Cultura de Minas Gerais; Superintendência de Bibliotecas Públicas, 2007. 223p.

IFLA. Manifesto IFLA/UNESCO sobre bibliotecas públicas: 1994. Disponível em: <http://archive.ifla.org/VII/s8/unesco/port.htm>. Acesso em: 30 set. 2012.

IFLA. Manifesto IFLA sobre Transparência, bom governo e combate a corrupção 2008. Disponível em: <http://www.ifla.org/publications/iflamanifesto-on-transparency--good-governance-and-freedom-fromcorruption>. Acesso em: 14 nov. 2013.

MANGAS, Sérgio. O papel político da biblioteca pública. Notícia BAD:

jornal dos profissionais de informação. Disponível em: <http://www.bad.pt/noticia/2011/08/25/o-papel-politico-da-bibliotecapublica/>. Acesso em: 15 nov. 2013.

MARTINS, Wilson. A palavra escrita: história do livro, da imprensa e da biblioteca. 3. ed. São Paulo : Ática, 2002. 519p.

PINHEIRO, Ricardo Queiroz. Biblioteca Pública: seu lugar na cidade. Revista CRB-8 Digital, São Paulo, v. 2, n. 1, p. 27-29, maio 2009. Disponível em: | <http://www.crb8.org.br/ojs/crb8digital>. Acesso em: 02 nov. 2013. 